\title{
HACIA UNA INTEGRACIÓN DE LOS SISTEMAS MÉDICOS: UTILIZACIÓN DEL AGUA EN LAS PRÁCTICAS DE MEDICINA TRADICIONAL Y MEDICINA NATURAL
}

\author{
por \\ J. ANTONIO FIDALGO SANTAMARIÑA
}

\section{1.- SISTEMA DE CULTURA Y ALTERNATIVAS MÉDICAS}

Las principales modalidades de respuesta que una sociedad elabora frente al problema de la enfermedad, se pueden incluir en alguno de los siguientes sistemas de medicina que aún se encuentran funcionando simultáneamente en nuestra sociedad gallega actual: A) El sistema de medicina «oficial» calificado de científico-experimental, y que, como es sabido, fue adquiriendo cada vez más importancia a medida que la religión y la magia cedían su campo a la investigación científica y técnica; B) El sistema de la medicina natural, que busca responder a la enfermedad a base de técnicas terapéuticas basadas en la utilización de elementos naturales, como por ejemplo la fitoterápia, dietética, nutricionismo, alimentación natural, o bien la hidrología (termalismo, balneoterapia), entre otras; C) El sistema de medicina tradicional, también llamada 'medicina popular' y 'medicina mágico-religiosa', que constituye una alternativa terapéutica mucho más antigua, tradicional y social, que la medicina moderna oficial.

De estas tres formas de respuesta todavía vigentes hoy en nuestro pueblo, y que podemos considerar esencialmente médicas, sin duda las que más me interesan, para el tema del que voy ocuparme, son las que integran los sistemas de medicina natural y medicina tradicional por cuanto, en

"CUADERnOS DE ESTUDiOS GALLEGOS", Tomo XLI, Fascículo 106, Santiago 1993-94. 
ellos, pacientes y «expertos» aparecen poniendo en juego otro tipo de lógicas paralelas a la lógica científica de la medicina oficial.

$\mathrm{Al}$ contrario de lo que acontece en el sistema médico científico-experimental, en el de la medicina tradicional se harán entrar, por ejemplo, la lógica de la maldad o de la mala suerte de la cual la enfermedad no es más que un caso particular; y para diagnosticar y tratar un mal determinado, en el sistema de medicina popular se permitirá acudir a un «médium» que no precisa haber pasado por la universidad, y que puede consistir tanto en la intervención de un santo, un sacerdote, una visionaria, una sabia ó una ensalmadora, como en un curandero, compositor u otra persona «experta» cualquiera, hombre ó mujer que los lugareños consideran aptos para practicar los procedimientos que en la comunidad se tengan por válidos para prevenir, curar, e incluso -en su caso- justificar la existencia de esta enfermedad.

Las observaciónes que siguen se centran en el uso del agua en las prácticas terapéuticas populares. Se trata sobre todo de identificar, primero la utilización que se hace de las diferentes clases de agua en los sistemas de medicina tradicional y natural, para a continuación determinar el sentido que presentan estos ceremoniales terapéuticos entre quienes los practican, aún hoy, en el seno de nuestras aldeas rurales, con el fin de prevenir, y sobre todo tratar de curar muy variados «males» que creen tener. El tema concluye proponiendo un modelo de análisis con capacidad de integrar los tres sistemas médicos diferentes -el oficial, el natural, el popular- que todavía se encuentran en nuestro entorno geográfico y sociocultural inmediatos, y a los que se acude para intenta resolver el problema de la enfermedad o el «mal», siempre presentes en todo grupo humano.

\section{2.- MIRADA A NUESTRO SISTEMA DE MEDICINA TRADI- CIONAL}

Es sabido que hasta no hace mucho tiempo, en el ámbito rural de Galicia las personas enfermas no eran atendidas por médicos sino por algún vecino entendido en remedios naturales para las enfermedades del ganado, y por personas que los lugareños llaman «curanderos», «compositores», entendidos», «sabias», «ensalmadores», y otros nombres que también se les da. Su conocimiento de muy variados remedios, recetas domésticas y procedimientos rituales con fines curativos les llega trasmitido oralmente de generación en generación, permaneciendo todavía algunos en la me- 
moria de la gente más vieja dispuesta aún a repetirlos cada vez que el pedido se produce. Pero nuestros antepasados no solamente acudían a estas prácticas para calmar sus dolencias, prevenir sus males, solucionar los problemas derivados de la enfermedad siempre presente. Si hacemos caso a los informes que hoy disponemos, da la impresión que en Galicia hemos acudido a todo cuanto existe para resolver los problemas derivados de la enfermedad, desgracia, infortunio individual ó colectivo. Cada síntoma de enfermedad se tiene convertido en una llamada hacia la ayuda de muy variados elementos del medio, tales como las piedras, el agua, rocío, sol, hiervas, árboles y otros múltiples elementos que se emplean en las prácticas terapéuticas populares, produciendo la impresión de que en Galicia casi todo sirve para curarnos de la enfermedad y el mal. Desde muy antiguo nuestros paisanos se han venido sirviendo para tratar sus «males», de diferentes tipos de piedras 'especiales' a las que atribuyeron propiedades profilácticas. Han hecho uso de las llamadas «piedras fertilizantes» con el propósito de volver fecundas las mujeres, consolidar el noviazgo, asegurar el matrimonio ${ }^{1}$, «pedras furadas» para curar a niños entangariñados y con otros males ${ }^{2}$, «pedras do raio» que se presentan como símbolo de fertilidad por tierras de la Gudiña (Orense), y con virtudes curativas «no mal da pezoña ou mordedura de animal venenoso», por las de Fonsagrada (Lugo) ${ }^{3}$. Tabién acudieron a las llamadas «pedra do coxo» con la que una vieja de Marván (Verín) curaba diversas dolencias, a la «pedra bezoar»o «pedra kaimán» que se emplea en la curación de varios males (mal do goxo, aire do sapo, pezoña da cobra, etc.), y a la "pedra corvina» tenída por buena para el mal nefrítico. Acudieron igualmente a otras piedras de las que Taboada Chivite dejó dicho, que nuestro pueblo les vino atribuyendo numerosas virtudes y propiedades profilácticas ${ }^{4}$. También han venido acudiendo nuestros paisanos a los cruces de los caminos («encruciladas») donde, por ejemplo, los habitantes de Sangenjo (Pontevedra) llevaban los niños para curarlos el «aire de encrucillada», ó bien iban tirar el agua de naviza

\footnotetext{
${ }^{1}$ Cfr. TABOADA CHIVITE, J.: Ritos y creencias gallegas. Gráficas MAGOYGO, La Coruña, 1980. Págs. 162-166

${ }^{2}$ Cfr. TABOADA CHIVITE, J.: Ritos y creencias gallegas. o.c., págs. 169-172

${ }^{3}$ Cfr. TABOADA CHIVITE, X.: Ritos y creencias... . o.c., pág. 183.

${ }^{4}$ Cfr. TABOADA CHIVITE, X.: Ritos..., o.c., págs. 150-184.

${ }^{5}$ Cfr. LIS QUIBÉN, V.: La medicina popular en Galicia. Akal editor, Madrid, 1980. Pág. 70
}

"CUADERNOS DE ESTUDIOS GALLEGOS", Tomo XLI, Fascículo 106, Santiago 1993-94. 
«ventureira» que han utilizado para curar sus males de «aire de sapo, gallina clueca o salamandra ${ }^{6}$. En un cruce de caminos también cortaban los de Lobeira (Orense) la cinta con se ataban las piernas del niño enfermo del «tangaraño» ${ }^{7}$, y en otra encrucijada rural del municipio de Caurel (Lugo), el padre del enfermo rompía «el puchero virgen» de barro que contuvo el agua usada por la 'vieja' ensalmadora en el ritual curativo del «entaranguiñado ${ }^{8}$. Ni tampoco nos han faltado viejos romeros que han peregrinado hasta la cima de algún monte galaico con intención de que los curase. A este respecto es sobradamente conocida por el poder salutífero que le ha sido atribuido, la cima puntiaguda del monte «Pico sacro», a la que acudieron nuestros antepasados enfermos para contemplarlo, hacerle ofrendas y pedirle salud. Tal como lo describe Bernardo Barreiro, el pueblo corrió hacia el Pico sacro acompañando al campesino enfermo, acercándose a él a través de otras montañas del Ulla, y deteniéndose «ya próximos, a contemplar la cima puntiaguda del coloso, creyéndole, aún, con la cabeza de un Dios, cuyo poder ha le de curar ...descubre la suya con respeto, se arrodilla con veneración, y dejando en tierra una corteza de pan en ofrenda, salúdalo lleno de fe con este pareado:

« Pico Sacro! ¡Pico Sacro!

Sácame de este mal que eu traio!»»»?.

De similar modo a como se ha hecho con los elementos citados, los hombres de nuestra sociedad tradicional acudía a muy variadas especies vegetales (árboles, plantas, hiervas, flores...) a las que atribuyen fines profilácticos, y, por supuesto, también al líquido elemento del que aquí voi a ocuparme: El agua en sus diferentes modalidades, esto es, agua natural caliente, templada, fría, helada; agua de río, de fuente, de rocío de la noche de San Juan, agua bendita el Sábado Santo, aguas del mar, y también aguas mineromedicinales y termales, como tendremos ocasión de observar.

\footnotetext{
${ }^{6}$ Cfr. LIS QUIBÉN, V.: La medicina popular.., o.c., pág. 58

${ }^{7}$ Cfr. LIS QUIBÉN, V.: La medicina..., o.c., pág. 72

${ }^{8}$ Cfr. LIS QUIBÉN, V.: La medicina..., o.c., págs. 100-101

${ }^{9}$ BERNARDO BARREIRO de W.: Brujos y astrólogos de la Inquisición y el famoso libro de San Cipriano. Arealonga, Madrid, 1973. Págs. 30-31
}

"CUADERNOS DE ESTUDIOS GALLEGOS", Tomo XLI, Fascículo 106, Santiago 1993-94. 


\section{3.- ETNOGRAFIA DEL USO DEL AGUA EN EL SISTEMA MÉ- DICO TRADICIONAL}

En el sistema de medicina tradicional el agua nos aparece como un elemento frecuente y esencial en el desarrollo de variadas prácticas terapéuticas. Una de las razones de su frecuencia se puede atribuír al hecho de que, en la mentalidad del pueblo el agua es un elemento fuerte, vital, donador de vida y salud. Considerada por el polígrafo gallego F. Bouza Brey, como «un ser que guarda vida y la otorga ${ }^{10}$, el agua ya fuera concebida por el filósofo griego Tales de Mileto como la esencia de todas las cosas. Esta fortaleza del líquido elemento sería lo que ha llevado, en la mentalidad popular, a considerar el agua como elemento superior a los demás, idea que será trasmitida por vía oral entre los miembros de la colectividad tal como se constata en variados segmentos de nuestro folclore popular. Uno de éstos, relativo al folclore infantil, es este en el que le canta al agua lo que sigue:

"Auga, que forte eres
que apagas o lume
que queima ao pau
que malla ao gato
que come ao rato
que fura o muro
que torna o aire
que corre a nube
que cubre a lua
que turba o sol
que derrete a neve
que no meu pé prende ${ }^{11}$.

Es en base a estas ideas de fortaleza superior y de fuerza salutífera y purificadora, que le son asociadas, que deberemos entender los usos varios que nuestro pueblo ha venido dando al agua en las diferentes profi-

\footnotetext{
${ }^{10}$ Bouza Brey, F.: «Los mitos del agua en el Noroeste hispánico», en: BOUZA BREY, F.: Etnografia y Folklore de Galicia, (1). Ediciós Xerais de Galicia, Vigo. 1982. Pág. 220

"Bouza Brey, F.: «Los mitos del agua..., en: BOUZA BREY, F.: Etnografia y Folklore de Galicia. o.c., págs. 220-221
}

"CUADERnOS DE ESTUDIOS GALLEGOS", Tomo XLI, Fascículo 106, Santiago 1993-94. 
laxis populares ${ }^{12}$. Por lo demás, todos estos empleos en ceremonias, prácticas y rituales terapéuticos en los que interviene el agua como un componente esencial más del ceremonial popular, pueden concernir tanto al plano de la vida colectiva (sequía prolongada, conflictividad) como a la vida personal (enfermedad, esterilidad, etc. de los individuos.

\section{1.- Prácticas terapéuticas con empleo de agua natural caliente}

Cuando el agua está caliente y por estarlo participa de las virtudes de ese otro elemento primario símbolo de vida por su continuo hacerse y deshacerse, cual es el fuego, ineludiblemente ha de contener propiedades salutíferas para aquella persona ó colectividad, que son objeto del ceremonial popular que se desarrolla con ella. Agua natural «templada» junto a otros elementos integrantes del ritual, es la que ha de usar la vieja «sabia» del Caurel (Lugo), para curar el niño 'entangariñado'. En la parte del ritual en que interviene el liquido elemento del ceremonial, la curandera procede como sigue según la siguiente información recogida por Lis Quibén:

«Cuando el agua está templada, la vieja hace sobre ella tres cruces con las seis pajas de trigo, otras tres con las seis hojas de olivo y otras tres con la cera derretida de la vela del Jueves Santo, que hicieron caer sobre el agua. Una vez hecho esto, empiezan a lavar el enfermo, nueve veces seguidas, de los pies a la cabeza, diciendo al mismo tiempo las siguientes palabras:

Se é mal de ollo, bótoche o fogo sácoche o collo e se-é aire de gata cadela ou muller a-elas se volva ser quen quixer

Una vez lavado el «entaranguiñado», cuelan el agua con un trapo bien limpio de lino y en él han de aparecer pelos de gata o mujer, si el «Aire» es de alguna de ellas $\rangle^{13}$

\footnotetext{
${ }^{12}$ Entre estos usos dados en Galicia, aparece su empleo tanto en los ritos profilácticos y de fecundidad, como en ritos adivinatorios y oraculares y en ritos pluviales. (Cfr. Bouza-Brey, F.: «Los mitos del agua...», en BOUZA BREY, F.:Etnografia y Folklore de Galicia, o.c., pág. 232

${ }^{13}$ LIS QUIBÉN, V.: La Medicina..., o.c., págs. 100-101

"CUADERNOS DE ESTUDIOS GALLEGOS", Tomo XLI, Fascículo 106, Santiago 1993-94.
} 
En el caso de que el agua caliente entre en combinación con la tierra, otro elemento primario, y si ésta ha sido extraída de una encrucijada o del cementerio parroquial, entonces se la considerará igualmente idónea para la curación del 'enganido'. La siguiente información dada al profesor C. Lisón Tolosana, por mujeres gallegas entendidas en el tratamiento de este mal, constata como previamente al lavado del enfermo las «expertas» preparan el agua caliente para desarrollar el ritual curativo del «enganido». El texto aparece recogido así:

«Xa habíamos antes fervido auga limpa e botado nove areas de terra dunha encrucillada pola que pasan os difuntos, nove areas de sal... e unha pouquiña terra (de la sepultura) do último que se enterrase na parroquia, todo nunha bolsa metida dentro dauga. O ferver (hay que) coller esa bolsa e tirala donde nunca mais se poidera hallar»y por Erbrón (Padrón) y por Boimorto «hay que ir al cementerio a las doce de la noche... Se pone el pie izquierdo en el suelo, se coge aquella tierra y se la da a tomar hervida en agua al niño» ${ }^{14}$.

Pero si bien nuestras «sabias» gallegas son mujeres ya ancianas y su ceremonial popular que practican se encamina a la curación del mal que presenta un individuo enfermo, en muchas otras comunidades lejanas denominadas sociedades «primitivas», va a ser el «gran sacerdote» del pueblo el que, en determindadas circunstancias, deba acudir al agua caliente, con el fin de proteger de los peligros los miembros de su comunidad. En su obra La rama dorada, J.G. Frazer nos da un ejemplo de esta costumbre de acudir al fuego y agua caliente, con fines protectores, en la isla indonésica de Timor. Aquí, el gran sacerdote ha de mantener el fuego encendido y beber agua caliente a fin de que nada ocurra a las personas mientras éstas se hallan luchando en la guerra. S.J.Frazer lo relata así:

«Mientras el ejército esta en guerra, el gran sacerdote no sale del templo. Allí come los alimentos que le llevan ó cocina, y día y noche debe mantener el fuego encendido, porque si lo dejase apagar sobrevendría el desastre, que se prolongaría mientras el hogar estuviese frío. Además, durante la ausencia del ejército, sólo beberá agua caliente, pues cada trago de agua fresca enfriaría el ánimo de la gente y de este modo no podrían vencer al enemigo» ${ }^{15}$.

\footnotetext{
${ }^{14}$ LISON TOLOSANA, C.: Brujería, estructura social y simbolismo en Galicia. Akal editor, Madrid, 1979. Pág. 126

${ }^{15}$ FRAZER, S. J.: La Rama dorada. Fondo de Cultura Económica, Madrid, 1989. Pág. 50
}

"CUADERNOS DE ESTUDIOS GALLEGOS", Tomo XLI, Fascículo 106, Santiago 1993-94. 
Se podría continuar constatando ejémplos etnográficos, pero basten éstos para confirmar este uso del agua tíbia o caliente en las prácticas terapéuticas populares. Pero esta capacidad protectora y curativa del agua no se limita solo al agua caliente, sino que igualmente se extiende a estos otros tipos de aguas frías de ríos, de fuentes, del mar, etc. algunas de cuyas prácticas delimitamos a continuación.

\section{2.- Prácticas terapéuticas con empleo de agua fría de los ríos}

También a las frías aguas de nuestros caudalosos ríos, y de los pequeños riachuelos que pasan cerca de los santurarios les atribuyó nuestro pueblo unas virtudes salutíferas especiales. El médico lucense J. Rodríguez López recogió este uso terapéutico que los vecinos de Coeses (Lugo) hacen de las aguas del río próximo a la Ermita del lugar. El investigador nos lo trasmite así:

«Siendo yo niño, estuve en aquella fiesta (de Coeses), y viendo la cantidad de gente que acudía a beber a un riachuelo que pasa cerca de la capilla, también yo bajé allí, donde me enseñaron un pequeño hoyo a la orilla, en donde recogen agua, no solo para beber en el acto, sino para guardar en botellas y llevarla a sus casas, como milagrosa para la curación de diversas enfermedades ${ }^{16}$.

Pero si en el caso que nos ocupa, estos vecinos de Coeses atribuyen la virtud salutífera de estas aguas al hecho de haber bebido la Virgen en aquél hoyo, según una vieja leyenda local, en otras ocasiones la razón del uso parece estar en relación con la fuerza destructora de las aguas, que fluyen arrastrando y destruyendo progresivamente todo cuanto sobre ellas cae, lo que no deja de ser justamente aquello que los lugareños pretenden que suceda con la enfermedad. Esto no ha de parecernos extraño ya que para curar la ictericia los parroquianos de Padrenda (Orense) también llevaban al enfermo a orillas de un regato que nunca «canse» (seque), y que una vez en dicho sitio, tal como informa Lis Quiben, «se persignan aquél y el curandero, rezan el Señor mío Jesucristo, y mojando el último una rama de carrasco en el agua, hace cruces sobre el enfermo recitando, al mismo tiempo, el siguiente ensalmo:

${ }^{16}$ RODRIGUEZ LÓPEZ, J.: Supersticiones en Galicia y preocupaciones vulgares. Ediciones «Celta», Lugo, 1974. Pág. 132

"CUADERNOS DE ESTUDIOS GALLEGOS", Tomo XLI, Fascículo 106, Santiago 1993-94. 


Blanca
encarnda
azul,
verdeada
morada
marela
amarela
anegrada
entripada
Teriz, enterrizada,
vaite deiquí
e non deixes nada.
Por la gracia de Dios
y de la Virgen María,
Un Padre Nuestro
y un Ave María.

Lo repite tres veces y rezan, a continuación un credo al Señor y una Salve a la Virgen María $\rangle^{17}$.

En otras zonas es el enfermo de ictericia quien deberá sumergirse descalzo en el curso del río con el propósito de que sus aguas contribuyan a curarle. Esto se constata en diferentes pueblos de la provincia de Coruña donde aparece recogida esta variedad de la práctica. En ellos, acompañantes y enfermo acuden a un cruce de aguas para practicar el ceremonial curador que se desenvuelve como sigue en esa fase en la que interviene el agua del río: «Va el paciente acompañado de otra persona, a donde haya un cruce de aguas; en él se mete descalzo, llevando las manos a la espalda y formando una cruz con los dedos pulgares. En esta posición el que le acompaña dice:

Eteriza cocheiriza;

negra, blanca, amarela, encarnada,

de calquer color que sea.

¡Maldita sea!

Vai polo río abaixo,

e tí limpo ó limpa quedas.

Po-lo poder de Jesús

e da Virxen María.

${ }^{17}$ LIS QUIBÉN, V.: La medicina..., o.c., pág. 280

"CUADERNOS DE ESTUDIOS GALLEGOS", Tomo XLI, Fascículo 106, Santiago 1993-94. 
Repiten tres veces esta oración y echan agua del río en la cruz que forman los pulgares, después de rezar tres veces un Padre Nuestro y un Ave María» ${ }^{18}$. En otras profilaxis el curso del río aparece sólo como un medio de distanciamiento y de eliminación de las vestimentas contaminadas por la enfermedad, de las que el paciente con intención de curarse ha de desprenderse. También a estos ceremoniales alude Rodríguez López situándolos en la zona de Tuy (Ponteverda), por donde, según nos informa, tratan de «curar algunos males extraños de los niños arrojando al río su ropa en una cestilla con una vela encendida creyendo que si, al arrastrarla las aguas, la luz no se apaga, curará el niño, y si se apaga no sanará ${ }^{19}$. Por su parte, en Puerto del Son (Coruña), constataba Lis Quibén que para curar a alguien de ictericia también se han de arrojar al río «dos hojas» de la «carrasca» bajo la que permanece sentado (el enfermo) durante el desarrollo de la práctica ritual propia de la curación de este mal $^{20}$.

Lo que parece estar indicándonos la comundad que desenvuelve estos ceremoniales profilácticos es el hecho de que, además de atribuir al agua en general esa fuerza purificadora, cuando se trata del agua corriente de un riachuelo o un manantial, el pueblo también confía en que ese agua «podrá llevar la enfermedad alejándola de la cercanía del paciente ${ }^{21}$. Estas corrientes de agua reciben lo arrojado en ellas y lo arrastran en su dirección hasta hacerlo desaparecer. Sobre todo cuando se trata del agua de río, esta manera de proceder en el ceremonal, ó en palabras del antropólogo C. Lisón, «la sinécdoque gestual no permite la duda en cuanto a la interpretación: la enfermedad, la desgracia, el mal es lo que simbólicamente arrojan al río -fuerza de la naturaleza- para que en su eterno fluir irreversible los arrastre para siempre, sin posibilidad de retorno, alejándolos en el olvido $\rangle^{22}$.

Para un tratamiento preventivo de otros males más complejos, como pueden ser, por citar un ejemplo relevante, los riesgos de aborto de las mujeres encinta, el pueblo dispone de otra serie de prácticas populares profilácticas que llevan a cabo, sobre todo, en los puentes de los ríos. Su

${ }^{18}$ LIS QUIBÉN, V.: La medicina..., o.c., pág. 209

${ }^{19}$ RODRIGUEZ LÓPEZ, J.: Supersticiones en Galicia..., o.c., pág.36

${ }^{20}$ Cfr. LIS QUIBÉN,V.: La medicina..., o.c., pág. 902

${ }^{21}$ MARIÑO FERRO, La medicina popular interpretada, I. Edicións Xerais de Galicia. Vigo, 1985. Pág. 54

${ }^{22}$ LISON TOLOSANA, C.: Antropología social: Reflexiones incidentales. Ed. CIS / Siglo XXI, Madrid, 1986, Pág. 68

"CUADERNOS DE ESTUDIOS GALLEGOS", Tomo XLI, Fascículo 106, Santiago 1993-94. 
objeto es evitar que un hijo, que aún no ha nacido, se malogre en el vientre de su madre. En estos casos el ceremonial popular va orientado específicamente a aquellas mujeres que no consiguen tener hijos, y se lo conoce, de modo general, como «Bautismo anticipado». Este ritual terapéutoco se efectúa en muchas zonas de Galicia cuando se cree que la madre va a malparir. En este caso se busca un puente por donde pase agua de mar o de río, al que acuden la madre y los familiares. Se espera que den las 12 de la noche y a la persona que pase le piden que bautice el ser que aún está en el seno de la madre. Se baja al río, se coge agua y se echa por el vientre de la madre de acuerdo con el procedimiento ceremonial y diciendo las palabras del ritual del bautismo. Disponemos de varias descripciones de la forma como llevan a cabo esta práctica terapéutica nuestros paisanos. Bernardo Barreiro recoge las versiones que de él hacen Andrés Muruais, narrada en verso, y Claudio Coello, descrita en prosa ${ }^{23}$; pero es el médico pontevedrés V. Lis Quibén quien describe más detalladamente el procedimiento del Bautismo anticipado muy extendido por la zona rural pontevedresa, especificando que el puente debe tener en el centro un crucero ó haberlo en sus inmediaciones, y que el momento en que ha de efectuarse el ritual debe ser inevitablemente a las doce de la noche, y lo tradicional es que se efectuase el último sábado de mes. Dado que los malos partos abundan en nuestra Galicia tradicional más que los puentes con crucero en medio, en el caso de que éste no se encuentre fácilmente se podrán desarrollar estos bautismos anticipados con agua de cualquier río y aprovechar el puente más próximo a la residencia de la mujer encinta. Por cuanto al desarrollo del proceso ritual en sí, que según Begoña Iglesias, puede efectuarse «encima de un puente» de agua dulce o de mar, «debajo del puente», «en una fuente que nunca seque», y aún «en la misma casa» de la madre, si se tiene fundada sospechas de que el niño no nazca vivo ${ }^{24}$, ha sido reconstruido por el citado médico pontevedrés Lis Quibén, de ésta manera:

«Una vez que la mujer, que no consigue conservar su familia, cae embarazada, la llevan a un puente, bajo el que discurre un río, en el que haya en el centro un crucero y en su defecto en sus inmediaciones, procurando esté allí un poco antes de las doce de la noche, acompañada de personas de su confianza, debiendo ir hombres

\footnotetext{
${ }^{23}$ Cfr. BERNARDO BARREIRO de W.: Brujos y astrólogos..., o.c., págs. 56-64

${ }^{24} \mathrm{Cfr}$. el desarrollo de las variantes citadas en: BECOÑA IGLESIAS, E.: La medicina popular gallega. MAGOYGO, La Coruña, 1981. Págs. 211-215
} 
y mujeres llevando una cesta bien repleta de comestibles, a base de carne sin distinción y un garrafón de vino del mejor. Llevan, además, una concha de vieira unas veces, otras sal en una cajita y agua bendita en un frasco, tras un cacharro de barro virgen y una cuerda, y otras, además de la concha de vieira, un ramo de olivo y un farol. Una vez en dicho sitio, colocan a la futura parturienta en el centro y a su lado el farol encendido y toman las entradas del puente, al objeto de que no pase persona alguna antes de la hora señalada y mucho menos un animal, como un perro o un gato, pues si así fuese habría que volver otro día, medida que toman también mientras dura la operación del bautismo, teniendo que guardar el más absoluto silencio, desde su llegada hasta que éste se efectúa y en tal sentido han de parar a la gente con señas.

$\mathrm{Si}$ aparece una persona un poco antes de las doce, le avisan de este modo para que espere y ha de ser precisamente la encargada de efectuar el bautismo. Llegada esa hora, una de las personas que esta en el extremo del puente por donde apareció, rompe el silencio y le fuerza que haga una alma cristiana y que bautice una criatura en el vientre de su madre. Una vez que accedió a tal pretensión la llevan a presencia de la mujer embarazada, pero mientras tanto y dure la ceremonia, siguen guardando las entradas del puente por el motivo apuntado. Entonces aquélla le dice: ¡Hombre o mujer que vienes de fortuna, bautízame esta criatura!. Es de notar que si es un hombre el primero que apareció, hace de madrina una de las acompañantes de la mujer embarazada y si es mujer, uno de los mismos.

Llegado el momento del bautismo, proceden en unas localidades de diferentes maneras que en otras y así cuando llevan la sal y el agua bendita, rezan en primer lugar el credo y después el padrino le echa la primera sobre el seno y la segunda, una vez la ropa levantada, sobre el vientre diciendo al mismo tiempo: Si é home Manuel se le pone, si é muller Isabel. Criatura, te bautizo en el nombre del Padre, del Hijo y del Espíritu Santo. Amen.

Como en la mayoría de las veces efectúan el bautismo en puentes bajo los que corre el agua mezclada de río con la de mar y en las mezclas altas solo de éste, ya no llevan la sal y el agua bendita, en cuyos casos, unas veces el padrino desde el puente recoge el agua valiéndose del cacharro y de la cuerda y otras baja, él precisamente, con la concha de vieira a recogerla y el bautismo lo hacen con el mismo ceremonial de antes, salvo que en el primer caso le echan 
sobre el vientre el agua del cacharro y en el segundo la de la concha. También recogimos más variantes en el sentido de mojar al ramo de olivo en el agua de la concha y bautizar con él o echar el agua de la misma, unas veces sobre la cabeza y otras sobre el pecho para que moje el vientre. Aún cuando citamos los nombres de Manuel e Isabel, en las palabras que pronuncian en el bautismo, lo corriente y usual es, que le den al padrino los nombres que le interesen a la madre que, como es natural, no siempre son los mismos.

Una vez terminada la ceremonia, la mujer cambia de ropa y después de elegir un buen sitio (algunas veces lo hacen debajo del mismo puente si el agua lo permite), a cenar todos juntos el contenido de la cesta y del garrafón, y después cada uno a su casa, siendo condición indispensable que antes tiren al río lo sobrante de la cena» ${ }^{25}$.

\section{3.- Prácticas terapéuticas con utilización de agua de las fuentes}

Un nuevo tipo de agua con propiedades salutíferas es la de manantiales o fuentes. El polígrafo gallego Bouza Brey consideraba que las propiedades curativas de los manantiales «han determinado en todos los tiempos una corriente de simpatía utilitaria hacia ellos» ${ }^{26}$. En su interior se hallan escondidos muy variados espíritus, divinidades protectoras y virtuosas ninfas que protegen y purifican sus aguas de virtudes curativas y salutíferas. Orientados por estas viejas creencias, nuestros paisanos acudíeron a ellos, en épocas pasadas, para tratarse de muy diferentes males por medio de sus aguas, e incluso para practicarlos un culto que luego la Iglesia cristianizó. Por todas partes de nuestra geografía se hallan muestras de esta forzada aculturación eclesial. Todavía hoy, tal como también dejó constatado Bouza Brey, «los edículos colocados sobre las fuentes de agua común conteniendo imágenes de bienaventurados del santoral cristiano, o muchas veces de la Madre de Dios en diversas advocaciones revelan la lucha sostenida por la Iglesia para arrojar de las fuentes a los dioses del paganismo de las viejas teogonías del noroeste hispánico» ${ }^{27}$. Son muchos los manantiales distribuídos por Galicia que siguen siendo hoy calificadas por nuestros

\footnotetext{
${ }^{25}$ LIS QUIBÉN, V.: La medicina ..., o.c., págs. 224-226

${ }^{26}$ Bouza Brey, F.: «Los mitos del agua...», en BOUZA BREY, F.: Etnografia y folklore de Galicia(1). o.c., pág. 232

${ }^{27}$ Bouza Brey, F.: «Los mitos del agua...», en BOUZA BREY, F.: Etnografia y Folklore de Galicia. o.c., pág. 232
}

"CUADERNOS DE ESTUDIOS GALLEGOS", Tomo XLI, Fascículo 106, Santiago 1993-94. 
paisanos de fuentes «benditas», «santas» ó «sagradas», por atribuirles virtudes profilácticas a sus aguas. Por las informaciones del investigador V. Martínez Risco, sabemos que son buenas para curar «todas las enfermedades» y especialmente las de los «ojos y la piel», las aguas de la fuente de la capilla de los remedios de la ciudad Orense; y para curar «los ojos, y también las llagas y heridas» las de la fuente de la capilla de Recesende, en Monforte de Lemos (Lugo); y que las aguas de la fuente Santa de Belmil, en Mellid (Coruña), se utilizan para curar «las dolencias del ganado ${ }^{28}$. Enumerar la lista de nuestras fuentes de agua virtuosa aportaría muy poco a nuestro tema, a no ser la reiteración de esa hipótesis ya formulada por V. Risco, de que «se debe tratar dunha tendencia ancestral moi fonda do noso pobo, a veneración das fontes, e que o seu culto debeo ser dos principais nos tempos da paganía ${ }^{29}$. Cuando el agua de estas fuentes «santas» y «milagreiras» se emplea a las doce de la noche del día de San Juán, o bien si se recoge para ser usada al rayar el sol de ese día, sus virtudes profilácticas se acrecientan hasta convertirse, según la creencia popular, en un remedio universal que merece ser aprovechado. Pero es, en especial, la «flor del agua», esto es, la que se recoge en la madrugada del día de San Juán antes de salir el sol, ó en el momento de salir e incidir sobre la capa superior de agua de la fuente, el agua más utilizada en los rituales curativos y preventivos de ese día debido a sus virtudes esenciales. Guardada y protegida por la legión de xanas, lavandeiras, vírgenes, encantos, hadas, damas, y demás ninfas habitantes de nuestras fuentes salutíferas, esta «flor del agua» se cree portadora de múltiples propiedades maravillosas quizás en virtud del contacto con todas las divinidades acuáticas citadas. Además de considerarla como elixir de belleza y de eterna juventud, nuestro pueblo cree que «la niña que al romper el día madrugue a coger la flor del agua, lleva en ella un tesoro de virtudes medicinales $»^{30}$. También se curará de sus males quien «a las doce en punto de la noche, sin temor a los encantos que salen, se lave en la fuente», y si la enfermedad contraída fuera la del bocio, se verá libre de ella quien beba «después de las doce de la noche de

\footnotetext{
${ }^{28}$ Cfr. RISCO, V.: «Etnografía. Cultura espiritual», en: OTERO PEDRAYO (Dtor): Historia de Galicia. 3 T. Akal editor, Madrid, 1979. T.I, pág. 275

${ }^{29}$ RISCO,V.: «Etnografía. Cultura espiritual», en: OTERO PEDRAYO (Dtor.): Historia de Galicia, o.c., pág. 410

${ }^{30}$ RODRIGUEZ LÓPEZ, J.: Supersticiones de Galicia..., o.c., pág. 143
}

"CUADERNOS DE ESTUDIOS GALLEGOS", Tomo XLI, Fascículo 106, Santiago 1993-94. 
San Juán el agua de nueve fuentes $»^{31}$. Lo extraordinario de estas aguas igual que del rocío de San Juán, del que me ocuparé a continuación, es que curan solamente en esta corta noche y durante el largo día que le sigue. Por lo que respecta a la «flor del agua», sólo en este día santificado es capaz de regenerar los cuerpos enfermos en base a esa fuerza vivificante del sol naciente que llega fecundando con su fuego intenso las aguas de nuestras fuentes, haciendo de ellas un símbolo de purificación y regeneración como él.

\section{4.- Prácticas terapéuticas con utilización del rocío de la noche de San Juán}

En los ceremoniales terapéuticos populares propios del día de San Juán se acostumbró a utilizar dos tipos especiales de agua: la de las fuentes tal como queda descrito, y el rocío («auga de orballo») caído esta noche que contiene, según la mentalidad popular, unas virtudes profilácticas especiales. Igual que el agua de las fuentes, el rocío de la noche de San Juán contiene propiedades del más diverso estilo. Si bien la «flor del agua» nos aparecía en conexión con los rayos del sol, el rocío («orballo») conecta con el mundo vegetal, que hace de él un elemento eficáz en una amplia serie de prácticas con propiedades curativas que han de aplicarse durante la noche y la mañana del día especialmente santificado. V. Risco nos describió como se hacía uso por todo Galicia del agua de rocío en esta noche, anotando entre otros aspectos que:

«Para curar a sarna, dormen os enfermos en coiro, antremedio do centeo, para colleren o orballo da noite toda; e métense polas searas molladas á mañanciña, enantes de sair o sol, como en Melide; ou emborcándose a esa hora na herba dos prados, como en Monterrei; ou refréganse contra dun carballo, ás doce da noite, diexando a roupa pendurda dunha ponla, como na provincia da Cruña ${ }^{32}$.

Aunque muchos también se sirvan del rocío de esta noche para matar la polilla de las ropas, dejándolas toda la noche colgando en las ventanas y balcones de la casa, sin embargo la enfermedad más combatida por él es la «sarna». Así en Narahío (San Sadurnino, A Coruña), de acuerdo con la información aportada por González Reboredo, «quén se arrolara o día de

\footnotetext{
${ }^{31}$ RODRIGUEZ LÓPEZ, J.: Supersticiones..., o.c., pág. 143

${ }^{32}$ RISCO,V.: «Etnografía. Cultura espiritual», en: OTERO PEDRAYO, R. (Dtor.): Historia de Galicia, o.c., pág. 679
}

"CUADERNOS DE ESTUDIOS GALLEGOS", Tomo XLI, Fascículo 106, Santiago 1993-94. 
San Xoán pola mañá no orballo íaselle a sarna ${ }^{33}$; y «para os sarnosos» de la parroquia de Xabestre (Trazo), también se utiliza el rocío de esta noche de San Juán, tal como recoge el estudio de C. Sixires sobre esta parroquia rural coruñesa ${ }^{34} ; \mathrm{y}$ lo propio sucede en Viana del Bollo según se constata en el estudio de Nicolás Tenorio sobre esta comarca orensana ${ }^{35}$.

No se precisa recabar más datos etnográficos para probar como la «flor de agua» y el «rocío» del día de San Juán, aparecen en el contexto de la mentalidad y la cultura popular como verdaderas fuentes de vida y salud. En tanto que elementos cargados de virtudes salutíferas maravillosas sirven tanto para emplear en las prácticas curativas a los enfermos de la vista, y a personas con erupciones cutáneas, sarna, etc., como para conservar más bellas nuestras campesinas jóvenes -dadas sus propiedades cosméticas que también se le atribuyen- al proporcionarles buen color y finura a su piel, y proteger su siempre pretendida eterna juventud.

\section{5.- Prácticas terapéuticas populares con empleo de agua bendita}

En la mayoría de los hogares de Galicia todavía se encuentra vigente una vieja costumbre de conservar alguna botella con «agua bendita», que se recoge en la Iglesia el Sábado Santo después de la ceremonia de su bendición. Esta clase de agua sigue siendo muy apreciada por nuestro pueblo que le viene dando, aún hoy, múltiples aplicaciones. Tradicionalmente, esta agua bendita se usó para «bendecir a casa pola Pascua, o leito tódalas noites, as sepulturas dos difuntos, os campos e os froitos. Para arredar ó Enemigo e pra votalo fora $\aleph^{36}$. Pero también constituyó un elemento que entra en muchos ceremoniales populares orientados a prevenir determinados 'males' ó bien a curarlos. Los múltiples ejemplos etnográficos que disponemos de su utilización en este ámbito prueban que estamos ante un elemento esencial, empleado en las terapias populares contra diferentes tipos de «mal do aire» como el «aire de sapo»" ${ }^{37}$, «Aire de

${ }^{33}$ GONZALEZ REBOREDO, X.M.: A festa de San Xoán. Ed. Ir Indo, Vigo 1989. Pág. 44

${ }^{34}$ Cfr. SIXIREI PAREDES, C.: Santiago de Xavestre. Chequeo a unha poarroquia rural. Ediciós do Catro, Sada (A Coruña), 1982. Pág. 178

${ }^{35}$ TENORIO, N.: La aldea gallega. Edicións Xerais de Galicia, Vigo, 1982. Pág. 142

${ }^{36}$ Risco, V.: «Etnografía. Cultura espiritual», en : OTERO PEDRAYO, R. (Dtor.): Historia de Galicia, o.c., pág. 367

${ }^{37}$ LIS QUIBÉN, V.: La medicina..., o.c., pág. 51

"CUADERNOS DE ESTUDIOS GALLEGOS", Tomo XLI, Fascículo 106, Santiago 1993-94. 
envidia $»^{38}$, «Aire de muerto ${ }^{39}$; de $«$ Mal de ollo $»^{40}$; contra la Eripsela ${ }^{41}$; la Caída de la paletilla ${ }^{42}$. Pero interviene también en la curación de paludismo $^{43}$, así como en ceremoniales de desconjuración de la casas ${ }^{44}$. En todos estos casos los recolectores describen, en sus trabajos, el lugar y papel de esta clase de agua en el proceso ritual. En calidade de ejemplo se puede constatar como el miembro enfermo de un paciente de «mal de sapo» se cura, en el Barco del Valdeorras (Orense), pasandolo «sobre los vahos que desprende una infusión de flores de romero, previamente secas, el agua bendita, que se recoge el Sábado de Gloria y cuya infusión ha de hacerse en un puchero nuevo y durante quince minutos» ${ }^{45}$; y en Redondela (Pontevedra, para curar el Aire de envidia y de excumulgado, se procede de este modo:

«Sobre unas brasas echan: incienso, agua bendita, aceite de lámpara del Santísimo, tres dientes de ajo, nueve de laurel, nueve de «trobisco», y hierbas de la noche de San Juan y, al salir el humo, pasan la criatura por encima, recitando al mismo tiempo el siguiente ensalmo:

Yo corto el codo,

el malo aire,

toda la mala Envidia,

todo el mal que aquí había.

Si es por hombre

por mujer

o por Excomulgado,

vete al infierno.

Con la gracia de Dios

y de la Virgen María,

Un Padre nuestro

y un Ave María.

Esto se hace durante tres días seguidos $»^{46}$.

\footnotetext{
${ }^{38}$ LIS QUIBÉN, V.: La medicina..., o.c., págs. 63-64

${ }^{39}$ LIS QUIBÉN, V.: La medicina..., o.c., pág. 65

${ }^{40}$ RODRÍGUEZ LÓPEZ, E.: Supersticiones en Galicia..., o.c., pág. 201

${ }^{41}$ LIS QUIBÉN, V.: La medicina..., o.c., Pág. 148

${ }^{42}$ LIS QUIBÉN, V.: La medicina..., o.c., pág. 65

${ }^{43}$ LIS QUIBÉN, V.: La medicina..., o.c., 288-289

${ }^{44}$ LIS QUIBÉN, V.: La medicina..., o.c., pág. 235

${ }^{45}$ LIS QUIBÉN, V.: La medicina..., o.c., pág. 51

${ }^{46}$ LUIS QUIBÉN, V: La medicina..., o.c., p. 63-64
}

"CUADERNOS DE ESTUDiOS GALLEGOS", Tomo XLI, Fascículo 106, Santiago 1993-94. 
Por su parte, en Marín (Pontevedra), la curación del aire de muerto se lleva a cabo mediante el siguiente ceremonial popular que Lis Quibén dejó descrito así:

«Encienden primeramente una vela, a continuación echan en una lata un poco de incienso y semillas de espliego y en otra lata un poco de agua bendita, se sientan, al mismo tiempo, el curandero y el enfermo, y aquél le pregunta a éste su nombre, calienta el primero, al calor de la vela, la punta de una navaja y con ésta coge un poco de incienso y semillas de espliego y, mientras arden, dice las siguientes palabras: «Antes que este mal sea visto, se retira el mal y viva Jesucristo» y esta última operación y estas últimas palabras las repite tres veces. Después cuelga del cuello del enfermo una Cruz de Caravaca, coloca sobre su hombro derecho un extremo de una estola y el otro sobre el suyo y lee en «El Ciprianillo» la primiera, segunda y tercera esconjuración y, a continuación , los Evangelios, $y$, siempre que aparece una cruz en el libro, moja en agua bendita una cruz pequeña de rosario, que previamente tiene en la mano, y bendice con ella tres veces al enfermo, en la cabeza y en los pies» ${ }^{47}$. Igualmente combaten ó previenen los efectos del Mal de ollo, llenando «un puchero con agua bendita y hacen cocer en ella un cuerno y tres piedrecitas cogidas en su camino por donde pasa el Viático, y después, de noche, así que se retira toda la gente, dejan delante de la casa el puchero volcado. Hay la creencia de que la persona que echó el mal del ojo arde si no viene a rogar que quiten el puchero de la puerta $\rangle^{48}$; y en la parroquia de Salcedo (Pontevedra), para tratar la Eripsela, «echan en un cacharro, agua bendita, y mojando en ésta una ramita de olivo, bendicen la parte enferma, pronunciando, al mismo tiempo, esta fórmula:

- ¿De dónde vienes, Pablo?

- Vengo de Roma

- Que traes de allá?

- D, con Deciplón

- Vólvete alá,

- Escúpete tres veces,

- y la $D$ desaparecerá.

${ }^{47}$ LIS QUIBÉN, V.: La medicina..., o.c., págs. 65-66

${ }^{48}$ RODRÍGUEZ LÓPEZ, J.: Supersticiones de Galicia y preocupaciones vulgares. o.c., Pág. 201

"CUADERNOS DE ESTUDIOS GALLEGOS", Tomo XLI, Fascículo 106, Santiago 1993-94. 
Lo hacen así una vez al día y durante tres seguidos» ${ }^{49}$. Por su parte en el Barco de Baldehorras (Orense), la Caida de la paletilla la curan «desnudando al enfermo y, mojando un ramo de olivo en agua bendita, le salpican con ésta, haciendo al mismo tiempo cruces en el aire y recitando lo siguiente:

Paletilla, Esiñela de F. de T.,

Viven e reviven como o cura no altar,

e volvan o seu lugar.

Con el poder de Dios,

y de la Virgen María,

rezando un Padre Nuestro

y un Ave María $\rangle^{50}$; y el paludismo, conocido vulgarmente con el nombre de «Terciana», «Terceáns o. Cuartás», lo curan en Cambados (Pontevedra) dando de beber al enfermo, al amanecer, agua bendita o siete tragos de agua en la que se hayan cocido garbanzos puestos siete días a serenar, reza el curandero y él una salve, y dice aquél las siguientes palabras:

Eu teño calentura e ti non, herbaboa

eiquí che traio sal e bróa

dalla a quen moe, e non a quen lle dóe» ${ }^{51}$.

Ya para concluir este epígrafe con algún ejemplo de ceremonial preventivo, anotaré este referido por Lis Quibén cuando describe que para desconjurar las casas, un brujo de Marín de Arriba (Pontevedra), «utiliza un cacharro con agua bendita y una cruz pequeña de rosario y mojando ésta en dicha agua, hace cruces en el aire al mismo tiempo que lee la primera, segunda y tercera excunjuración de «El Ciprianillo» $»^{52}$.

\section{6.- Prácticas terapéuticas populares con empleo de agua de mar:}

De acuerdo con la siguiente anotación proveniente de V. Risco, los marineros de las rías pontevedresas procuran tener contento el mar echándole un trozo de pan de maíz al salir fuera de sus puntas ${ }^{53}$. Sus aguas,

\footnotetext{
${ }^{49}$ LIS QUIBÉN,V.: La medicina..., o.c., pág. 148

${ }^{50}$ LIS QUIBÉN, V.: La medicina..., o.c., pág. 175

${ }^{51}$ LIS QUIBÉN, V.: La medicina..., o.c., pág. 289

${ }^{52}$ LIS QUIBÉN, V.: La medicina..., o.c., pág. 234

${ }^{53}$ RISCO, V.: «Etnografía. Cultura espiritual», en: OTERO PEDRAYO, R. (Dtor.): Historia de Galiza , o.c., pág. 274
} 
piensan muchos marineros y campesinos del interior, están dotadas de unas propiedades que en ciertas circunstancias se pueden poner al servicio de los humanos. Considerado en la mentalidad popular como un espacio sagrado, al agua del mar también le serán atribuídas virtudes para muchas cosas. Puede servir, incluso, para curar la rabia si tomamos en consideración los siguientes versos de Rodríguez de Padrón, recogidos en un trabajo de Taboada Chivite:

«No cesando de rabiar

no digo si por amores,

no valen saludadores

ni las aguas de la mar» ${ }^{54}$.

Son, no obstante, las aguas de algunas de nuestras playas las que mayores propiedades salutíferas encierran. Así, el agua de la playa de la Lanzada (Pontevedra) contiene, según recogemos de un informe de Taboada Chivite, una «doble eficacia: Profilaxis contra toda dolencia y hacer fecundas a las estériles $\rangle^{55}$. Todos quienes renovaron la costumbre ancestral de tomar en esta playa las nueve olas lo han hecho tanto para curarse del «meigallo» como, si son mujeres, para quedar embarazadas. Las propiedades contra el meigallo aparecen recogidas en este canto popular marinero que dice:

«Levei a miña muller

á Lanzada, ás nove olas;

leveina a desenfeitizar

a votar os demos fora $\rangle^{56}$.

$\mathrm{Si}$ a lo que aspira la mujer es a tener hijos buenos y fuertes, en este caso el baño de las nueve olas lo ha de tomar completamente desnuda ó bien vestida con un camisón blanco el día de la Ascensión, el día de San Juán antes de salir el sol, o bien al amanecer del último domingo de Agosto. De acuerdo con el siguiente comentario de V. Risco, este baño fertilizador de las nueve olas «consiste en meterse no mar e deixaren pasar por riba do corpo nove olas. Mais pola maneira de votaren as contas, semella que as

${ }^{54}$ Taboada Chivite, J.: «La noche de San Juán en Galicia», en TABOADA CHIVITE, J.: Ritos y creencias gallegas. MAGOYGO, A Coruña, 1980. Pág. 20

${ }^{55}$ Taboada Chivite, J.: «La noche de San Juán..., en: TABOADA CHIVITE, J.: Ritos y creencias..., o.c., pág. 20

${ }^{56}$ LANDIN CARRASCO, A.: «Cantares marineros Gallegos», en : Cuadernos de Estudios Gallegos, Tomo X, 1955. Pág. 283

"CUADERNOS DE ESTUDIOS GALLEGOS", Tomo XLI, Fascículo 106, Santiago 1993-94. 
que teñen virtude non son nove senón sete. Efectivamente, contan nove, dende que se meten, mailas que realmente reciben son sete a partir da terceira que contan $\rangle^{57}$. Si bien es cierto que este ceremonial profiláctico se vino practicando sobre todo en la hermosa playa de la Lanzada (Noalla. Pontevedra), también se sabe que hasta hace poco tiempo se llevaba a cabo igualmente en otras playas gallegas como la playa de placeres (Pontevedra), y San Andrés de Teixido (Coruña). Ambas playas, tal como observa F. Alonso Romero en un trabajo sobre este ritual popular ${ }^{58}$, también conservaban este poder salutífero y fecundador de nuestras mujeres estériles, con deseo de tener hijos, y de igual modo, la playa de «San Francisco junto a Louro (Muros)» a donde iban a tomar las nueve olas la mañana de San Juán, las mujeres que no tenían niños ${ }^{59}$. Lo simbólico de la cifra neuve nos evoca el período de gestación y el nacimiento; el problema de esterilidad que sufre el enfermo debe desaparecer después de estas nueve inmersiones en las aguas de la mar sagrada.

\section{UTILIZACIÓN DEL AGUA EN EL SISTEMA DE MEDICINA NATURAL}

Este otro recurso a las aguas minero-medicinales y termales para responder a las dolencias aparece documentado desde la remota antigüedad. Ya Plinio el Viejo, refiriéndose a esta clase de agua, constataba en su Historia natural que «el agua sulfurosa es buena para los nervios, el agua aluminosa para las parálisis y asténias del mismo género, el agua bituminosa o nitrosa -como la de Cutila-para la bebida y para la purga $\rangle^{60}$, y exponía además, como debía hacerse un correcto uso terapéutico de

\footnotetext{
${ }^{57}$ RISCO, V.: «Etnografía. Cultura espiritual», en OTERO PEDRAYO (Dtor.) Historia de galicia..., o.c., 1979. Pág. 275

${ }^{58} \mathrm{Cfr}$. ALONSO ROMERO, F.: «As nove ondas da mar sagrada»: Ritos y mitos galaicos sobre las olas del Mar», en: Cuadernos de Estudios Gallegos. Tomo XXXIII (1982), $\mathrm{N}^{\circ}$ 98. Pág. 591

${ }^{59}$ Dato etnográfico que recojo del profesor C. Lisón, quien lo recibió así de una informante de la zona: «Aquí [Playa de San Francisco] existéu a costumbre das nove olas pras mulleres que non tiñan meniños. Existéu; oí falar desto. E viñan de Muros aqui. E as que querían ter novio viñan a tomar aquí nove golpes do mar seguidos, en a mañá de San Juán, outro día non valía». LISON TOLOSANA, C.: Antropología social: Reflexiones incidentales. o.c., pág. 64.

${ }^{60}$ PLINE L'ANCIEN: Histoire Naturelle. Société d'Editions «Les Belles Lettres», París, 1972. Livre XXXIII. Cap. XXXII: 59
}

"CUADERNOS DE ESTUDIOS GALLEGOS", Tomo XLI, Fascículo 106, Santiago 1993-94. 
éstas aguas minero-medicinales y calientes ${ }^{61}$. Por lo que atañe a nuestro territorio las fuentes de aguas minero-medicinales son en él abundantes y de muy diferentes propiedades, lo que provocó que muchas personas acudieran a ellas para intentar curarse de las más variadas afecciones. Aún hoy escucho a menudo los favores de las aguas de las «Burgas» ó del «Tinteiro», en la ciudad de Orense. Es sabido por los datos que nos ofreció Risco, que el agua de las Burgas viene siendo aplicada por el pueblo, lavándose con ella en los caños, para librarse de «andacios e pestes», y bebiéndola tres días seguidos en ayunas, «contra costipados e doenzas do peito»; $y$ sobre el agua de la Burga de Baños de Molgas también nos informa V. Risco que bebida al acostarse «cura los costipados», y lavándose con ella «cura inflamaciós» ${ }^{62}$. A otras muchas les ha sido atribuídas propiedades salutíferas especiales, como las aguas de las fuentes de aguas mineromedicinales de La Guardia (Orense), la Toja y Partovia (Pontevedra) que se dice que curan -o que aceleran la curación- tipos varios de procesos reumáticos, tales como reumatismos crónicos (artritis reumatoide, fibrositis, gota, etc.), y diferentes tipos de secuelas de traumatismos de los pacientes. A las aguas de las fuentes minero-medicinales de Caldas de Reyes y de Caldelas de Tuy (Pontevedra) les son atribuídas propiedades para curar las afecciones del aparato respiratorio y otorrinolaringología (manifestaciones congestivas, edematosas, secretoras); $y$ las fuentes minero-medicinales de Verín y Carballiño (Orense), Mondariz (Pontevedra), Guitiriz (Lugo) se las considera muy buenas para las afecciones de hígado y vías biliares. De las aguas de la fuente minero-medicinal de la isla de la Toja (El Grobe, Pontevedra) y de la parroquia de Berán (Leiro, Orense), se considera que tienen propiedades curativas para las afecciones dermatológicas. En una de mis visitas al lugar de baños de Berán (Leiro) he podido constatar el nutrido número de bañistas con soriasis que llegaban hasta aquél escondido «lugar de baños», con el propósito de practicar un número determinado de baños en las aguas del reducido y contaminado estanque, o bien en algunas de las viejas bañeras controladas por la campesina encargada.

Pero se ve razonable que la mayoría los parajes en donde manan aguas mineromedicinales con propiedades especiales, hayan llegado a convertirse con el tiempo en unos lugares privilegiados destinados a irradiar salud.

\footnotetext{
${ }^{61}$ Cfr., PLINE L'ANCIEN: Histoire Naturelle, o. c.: Livre XXXIII, Cap. XXXII: 60.

${ }^{62}$ Cfr. RISCO.V.: «Etnografía. Cultura espiritual», en: OTERO PEDRAYO, R. (Dtor.): Historia de Galiza, o.c., pág. 175
} 
Algunos han permanecido como simples manantiales frecuentados por los lugareños y gentes de la comarca deseosas de curarse por medio de sus aguas, tal como sigue a ocurrir las fuentes de las «Burgas» y del «Tinteiro» en la misma ciudad de Orense. En otros casos como el de Berán, llegaron a disponer de algunas bañeras para tomar los baños salutíferos. Están por último aquellos manantiales que se transformaron en los actuales Balnearios y Villas Termales oficiales. Aunque en muchos de ellos las reglas de vida salutífera estén programadas mucho más para las personas sanas que para las privadas de salud, en cualquier caso considero que las diferentes prácticas hídricas que se pueden efectuar en ellos así como la mayoría de los comportamientos que ponen en práctica aquellos residentes necesitados de curación, nos están remitiendo mucho más al contexto de las prácticas propias de la medicina popular, que al que al de la medicina moderna $u$ oficial. En efecto, bajo la apariencia de practicar un tipo de medicina muy próximo a la medicina oficial los balnearios vienen a constituir un ámbito determinado del sistema médico tradicional por cuanto en esta práctica terapéutica se da, tal como sucede en el sistema de medicina tradicional, una íntima conexión y un pacto entre lo terreno y lo celeste, entre lo humano y lo sobrenatural. De un modo similar a lo que ocurre ante cualquier santuario «milagreriro», fuente «santa», día santificado ó encrucillada numinosa, también en estos espacios naturales beneficiados por los dioses se continúan perpetuando tradiciones ancestrales, al tiempo que se entremezclar y combinan unas prácticas y procedimientos empíricos con sólidas actitudes de fe y de esperanza. Con más frecuencia de lo se puede esperar lo que va buscando en el balneario el demandante de crenoterapia, no es solo la curación somática y psicológica de la enfermedad para lo que cree ser buenas sus aguas sino, sobre todo, un refugio donde descansar, esparcirse y huir del estres. A buen seguro que se busca, sobre todo lo demás, un lugar adecuado donde conseguir superar los conflictos y tensiones propios del medio en que viene realizando su vida y trabajo, y una forma de instaurar nuevamente el reequilibrio psicosocial.

\section{SOBRE EL SIGNIFICADO DE LAS PRÁCTICAS TERAPÉU- TICAS QUE SE RELACIONAN EN EL ESTUDIO}

Tal como expresa F. Saillant en su estudio de las recetas de medicina popular, «el trabajo del antropólogo no consiste únicamente en encontrar 
y dar cuenta de la organización cultural de las prácticas, en un momento dado; consiste también en encontrar el sentido y la coherencia de estas prácticas en tanto que producto histórico y cultural ${ }^{63}$. Es de esta búsqueda de coherencia y significado cultural aribuíbles a las prácticas y ceremoniales terapéuticos que hemos constatado, de lo que voy a ocuparme en esta parte final estudio. En dicha búsqueda deberemos tener en cuenta no solo el hecho de que la existencia de enfermedades, «males» e infortunios se pierde en la noche de los tiempos, y tiene una existencia universal, sino que la especie humana ha creado unas respuestas a los mismos adaptadas a cada contexto cultural. A este respecto, se puede decir que siempre que el problema de la enfermedad se hace presente en una sociedad, ésta generará unas modalidades específicas de respuesta orientadas a diagnosticarla, tratarla y hasta a justificar la existencia de la misma en su seno.

Limitándo el análisis solo al ámbito de nuestra sociedad gallega, podemos advertir aún hoy como nuestros habitantes del mendio rural y urbano siguen disponiendo, para responder a los variados tipos de enfermadades y males que á menudo les sobrevienen, de los tres modelos de respuesta terapéutica ya enumerados al principio de este estudio, a saber: El modelo biomédico, ó de la medicina oficial o científico experimental; el modelo de la medicina natural, en el que se pueden incluir las prácticas propias de la balneoterapia, crenoterapia, hidroterapia, hervoroterapia, etc; y el modelo de la medicina tradicional o popular, también denominada medicina mágico-religiosa. Y el contenido específico de estas diferentes estratégias terapéuticas es posible situarlo en el distinto grado de humanismo y sociabilidad que presenta cada sistema médico señalado.

Ciertamente, aquellas respuestas que se hacen provenir del modelo biomédico parten siempre de una concepción científica del problema; ante la solicitud social de respuesta al problema, los «expertos» del modelo biomédico ponen en juego la lógica del científico experimental y conciben la enfermedad como un hecho que se manifiesta a través del cuerpo por medio de unos síntomas, que pueden ser descritos objetivamente y regulados por un tratamiento alopático de carácter químico; un tanto prisionero de un tipo de racionalidad biologicista y del método científicoexperimental, estos «expertos» en biomedicina van a interpretar las molestias de sus pacientes de acuerdo con el repertorio de modelos

${ }^{63}$ SAILLANT, F.: «Les recettes de médicine populaire. Pertinence anthropologique et clinique», en: Anthropologie et sociétés,(1990) vol.14, nº1, págs. 93-114. Pág. 110

"CUADERNOS DE ESTUDIOS GALLEGOS", Tomo XLI, Fascículo 106, Santiago 1993-94. 
interpretativos al uso en su medio (biomédico, inmunológico, viral, genético, ambiental, psicodinámico, etc.), y todo síntoma que no encaje en ellos es considerado como inexistente, ó interpretado como de origen psíquico. Así de inmersos en un racionalismo puramente biológico, las intervenciones terapéuticas de los «médiums» van a consistir en unos 'actos técnicos' desprovistos de todo soporte social y humano. De este modo es fácil comprobar en el interior de nuestras clínicas más avanzadas como los síntomas de la enfermedad son descodificados e interpretados por los especialistas de acuerdo con estos repertorios de modelos interpretativos imperantes, sin tomar en consideración la persona del paciente, su personalidad, su ambiente y medio social, su tipo de vida, etc. En base a esto, y aún admitiendo su eficacia probada en lo referente al diagnóstico y tratamiento de la enfermedad, a esta modalidad de enfrentarse al problema de la enfermedad que porpone el modelo biomédico le encotramos ciertos fallos de diagnóstico y riesgos de deshumanización, por lo que nos sumanos a las críticas que le hacen aquellos autores que califican este sistema médico de «reducionista», por considerar que empobrece significativamente la labor terapéutica de la medicina moderna ${ }^{64}$.

Bastante más humanista y social es ya la estrategia que pone en práctica el modelo de la medicina natural. Limitándo mi reflexión sólo al campo de la hidroterapia, balneoterapia y crenoterapia y otras prácticas terapéuticas que se desenvuelven en los balnearios y villas termales receptoras de pacientes, se observa, en una primera aproximación, como también en ellos se aprecia el esfuerzo de los «médiums» por reproducir en estos lugares de salud aquello que es obligatorio en las clínicas del modelo médico oficial. En efecto, igual que en cualquier clínica particular ó pública también estas instalaciones balneareas cuentan con oficina de recepción, sala de espera, un ambiente hospitalario en los lugares donde todo debe estar aséptico, recomendaciones de guardar silencio, prohibición de fumar, uniforme blanco de los «médiums», etc., etc. Pero a diferencia de aquellas, -y en esto basamos su diferencia de ellas-, los tratamientos terapéuticos a los que se someten los necesitados de salud presentan unos rasgos que los separa de aquellos propios del sistema médico oficial, aproximándolos mucho a los de la medicina tradicional. En efecto, aunque se trate de unas prácticas terapéuticas que sufren continuas transformaciones y cambios adaptativos

${ }^{64}$ Cfr. DUNCAN PEDERSEN: «Curanderos, divinidades, Santos y doctores», en: América Indigena, Vol. XLIX, núm.4, octubre-diciembre de 1981. Pág. 659

"CUADERNOS DE ESTUdIOS GALLEGOS", Tomo XLI, Fascículo 106, Santiago 1993-94. 
a las nuevas exigencias del demandante de salud, y de la sociedad general, la mayoría de los procedimientos terapéuticos que se desarrollan en estos «sanatorios sociales» se pueden calificar en cierto sentido de prácticas terapéuticas tradicionales, por cuanto para ser llevadas a cabo no se precisa de la mediación de un médico, u otra clase «experto», o grupo de «expertos» componentes de alguna institución oficial. La medicina natural se nos presenta, tal como se desarrolla aún en la actualidad, mucho más ligada con la noción de 'tradición' -por 'tradición' no ha de entenderse 'inamovilidad'- que con las de modernidad y de ciencia. De otra parte, en el marco de los balnearios es fácil encontrarnos también ante la presencia de prácticas terapéuticas que combinan deliberadamente creencias y prácticas de la religiosidad popular con otros procedimientos empíricos. Pensamos que no es posible desligar nuestras fuentes termales y mineromedicinales de su relación con cultos antiguos a divinidades precristianas. Igual que otras muchas fuentes de Galicia, también las fuentes termales tienen sus «númenes» a los que nuestros remotos antepasados han dado culto. F. Bouza brey, alude en un versado trabajo de 1942 sobre 'los mitos del agua en el noroeste hispánico', al dios «Edovio» como al dios de las aguas termales de Caldas de Reyes (Pontevedra), y al dios «Bormánico» como a otro númen del agua termal $\gg^{65}$, y la misma conexión entre divinidades y aguas termales aparece en otro estudio que publica en 1956, sobre la inmersión de los «sacra» y los viejos cultos hídricos», donde expresa que «o deus Bormánico, que recebeu culto en Vizella (Minho) é un deus de auga termal, relacionado con un topónimo Bormo ou Borbo que está relacionado na Galia en diversas fontes antigas. O deus Edovio aparece vencellado cas augas termales de Caldas de Reis (Pontevedra) por un único epígrafe adicado por un celta romanizado: Adalos Cloutai ${ }^{66}$. Pero al margen de ese vínculo innegable de las principales divinidades con esos espacios de salud, mantenido desde antiguo por nuestro pueblo, todavía hoy no es difícil comprobar en el seno de estas estaciones termales, como continúan cohabitando los conocimientos científico-experimentales con los de de la medicina

${ }^{65}$ Cfr. BOUZA BREY, f.: «Los Mitos del agua en el <Noroeste hispánico», en: Etnografia y Folclore de Galicia, o.c., pág. 229. La versión original de este trabajo aparece en: Revista General de la Marina, vol. CXXIV, 1942

${ }^{66}$ Bouza Brey, F.: «Ritos impetratorios da choiva en Galiza: A inmersión dos «sacra»e os vellos cultos hídricos», en: BOUZA BREY, F.: Etnografia y folklore de Galicia (1). o.c., pág. 137

"CUADERNOS DE ESTUDIOS GALLEGOS", Tomo XLI, Fascículo 106, Santiago 1993-94. 
popular, y las técnicas empíricas que se sitúan al lado de lo natural, lo profano y lo corpóreo del paciente, junto a otros ritos de religiosidad popular que se ubican del lado de lo espiritual, de la fe y creencias del enfermo; tal como suele acontecer en el marco de la medicina tradicional también en este ámbito de la medicina natural del balneario, el entendimiento de las dolencias del cliente, su explicación y tratamiento aparecen relacionados con el punto de vista del paciente, con sus creencias sobre el mal y generales, su ideología, etc.. De un un modo similar a como ocurría en los superficies ceremoniales de las fuentes, ríos, playas, también en el interior de nuestros balnearios es fácil descubrir esa estrecha relación, siempre negada por la medicina «oficial», entre «lo médico» y lo religioso, y entre la salud y la salvación. Por lo general, los clientes de nuestros balnearios siguen siendo ciudadanos que no reniegan del modelo médico oficial basado en el experimento científico, pero tampoco del modelo de medicina natural basado en una contrastada «empiría» popular, ni aún de las posibilidades terapéuticas de los otros bienes de salud ó de salvación que integran el amplio abanico de recetas familiares, ensalmos y ceremoniales de carácter popular, exvotos y demás promesas a los santos milagreros comarcales ó locales. Se trata de un colectivo de clientes aún muy particular al que nada se le presenta rechazable y a todo esta en disposición de acudir, con tal de incrementar su nivel de salud física, social y moral, al que aspira.

En definitiva, la mayor parte del éxito de la cura balnearia se puede atribuir a este sincretismo de lo natural y lo cultural, de lo empírico y lo simbólico que en ella se produce. Convengo con García Guillen en que «además de los efectos físicos producidos por las aguas, la acción de los baños es atribuible a los efectos morales del medio en que se toman. El balneario es un microsistema cultural y sanitario. Es el lugar ideal para establecer un régimen de vida sano e higiénico» ${ }^{67}$. Las condiciones de vida y del ambiente tranquilo y saludable que en ellos se ofrece, es la mejor respuesta a los diferentes problemas de salud con los que creen llegar los usuarios estacionales. Será debido a esto que de acuerdo con su significado y orientación original, los actuales Hoteles-balneario y Estaciones termales procuran disponer cada vez de mejores instalaciones destinadas tanto a la cultura física (gimnasio, piscina, espacios destinados

${ }^{67}$ GARCIA GILLEN, d.: «Lo físico y lo moral en la cura balnearica», en Bol. Soc. Hidrol. Méd., Vol III, nº1, 1988, 5-10. Pág.9

"CUADERNOS DE ESTUDIOS GALLEGOS", Tomo XLI, Fascículo 106, Santiago 1993-94. 
al esparcimiento) como a la cultura intelectual, espiritual y simbólica (jardines con templos, tiendas, galerías ajardinadas para paseo, biblioteca, sala de conferencias, etc.); y que la función de los «médiums» de la institución sea sobre todo la de regular el orden de vida sana de la institución, y de hacer que se cumpla ese régimen de vida saludable, sobrio, funcional, relajado, sano entre los solicitantes de este servicio de salud. Auténticos microsistemas sanitarios y culturales, lo que produce en los balnearios el reequilibrio orgánico y psíquico -cuando lo producen- es además de las propiedades salutíferas de sus aguas, toda la serie de factores ambientales, costumbres y condiciones de vida saludable que en ellos se desenvuelve. Vemos por lo demás que la «regula vitae» del hotel balneario actual, ya no se instituye hoy para alguien que está enfermo sino para el sano; en él todo aparece funcionañdo como si se estuviese sano: Aplicación de baños con temperatura alterna así como de vapor en sudarios similar a como hacían antaño nuestros ancestros romanos en sus baños públicos; confortable residencia, jardines, ermitas, campos de deportes, restaurantes, bares..., todo ello para mejor combinar la infraestructura y cultura sanitaria (médicos, dietólogos, fisoterapeutas, psicoterapeutas, etc.) con los demás aspectos de una vida lúdica y de bienestar propios de la postmodernidad; y es que si como es sabido cada cultura genera sus propias enfermedades, también cada cultura se nos presenta como un sistema de tratamiento de la enfermedad. Es a partir de bases de análisis como la que aquí se propone, desde donde considero que se puede comprender el destino actual y el futuro de nuestro sistema de medicina natural y balneoterapia, así como las posibilidades de éxito terapéutico entre los demandantes de sus servícios profilácticos, en especial, los veraniegos.

Aún más humanas y sociales que las respuestas dadas a los problemas de la enfermedad y del mal por el modelo de la medicina natural, se puede decir que son las series de respuestas generadas por el sistema de medicina tradicional o medicina popular. Si bién en la medicina natural aún podíamos distinguir en cierta medida lo natural y lo espiritual de la práctica terapéutica, en la medicina tradicional ya somos prácticamente incapaces de discernir esa frontera que separa lo humano de lo divino, lo profano de lo sagrado. La propia cosmovisión que la gente del campo tiene del mundo centrada en una concepción maniquea del mismo, les posibilitará explicar cualquier dolencia y malestar orgánicos por medio de la acción maléfica de un espíritu malo que siempre acecha a los lugareños. En base a esto se entiende fácilmente como entre nuestros paisanos, cada tipo de enfermedad 
o de mal que no sea específicamente de médico por ser producido por un «aire» especial, un espíritu, o mismo la propia «voluntad divina», tenga también su receta cultural adecuada y su agua preferida (de rocío del día de San Juán, de fuente santa, de río, fría, caliente, salada, minero-medicinal, etc.), y movilice los miembros del grupo más adecuados y precisos en número para desarrollar el remedio eficaz o bien el ceremonial curador.

Una función esencial de estos 'médiums' será la de localizar el mal y utilizar lo que la cultura lugareña les ofrece para restablecer el bien (salud), o en su defecto elaborar una explicación del fracaso. Los intervinientes en el proceso ritual tienen las reglas a su disposición y experimentan con ellas, lo que viene a ser igual a experimentar sobre ellos mismos. La situación ceremonial les está obligando a contemplarse actuando, a sumergirse, tal como escribe J.L García, «en el torbellino mismo de la tensión entre realidad y ficción, entre lo necesario y lo contingente, para volver a salir ranacidos, reintegrados o transformados y dispuestos a conducir su vida social en otra dirección ${ }^{68}$. A diferencia del lenguaje científicoexperimental propio de los profesionales de la medicina oficial, el idioma de los protagonistas de estos rituales populares terapéuticos con uso del agua, es el de la estructura social. En el escenario del ritual terapéutico, pacientes, 'médiums' ('expertos'), y acompañantes (pueblo), aparecen utilizando los principales medios de la cultura lugareña, y el ceremonial terapéutico se nos transforma en un auténtico metacomentario de su propia realidad social. Para solucionar el problema que presentan sus miembros, la misma sociedad usa un contexto estratégico, y los actores del ritual «se guían por un proceso ritual estricto en el que aparecen las fases siguientes: Quiebra, crisis, acción renovadora, conclusión, ya sea por retorno, por restauración de una situación «normalizada» o por la aceptación consensuada de una quiebra irremediable y, por tanto, de un nuevo orden ${ }^{69}$. Se trata de unos rituales terapéuticos populares por medio de los que los actores buscan simular el tránsito del paciente del estado de enfermedad al de salud, que se hallan muy lejos de los 'actos técnicos' propios del modelo triunfante de la biomedicina ó medicina oficial. Sobre esta base de análisis se entiende como las diferentes prácticas referidas de medicina popular, se coloquen al margen

${ }^{68}$ GARCÍA, J.L., y otros: Rituales y proceso social: Estudio comparativo en cinco zonas españolas. Ministerio de Cultura, Madrid, 1992. Pág.13

${ }^{69}$ Cfr. GARCÍA, J.L. y otros: Rituales y procesos ...., o.c., pág. 13

"CUADERNOS DE ESTUDIOS GALLEGOS", Tomo XLI, Fascículo 106, Santiago 1993-94. 
del racionalismo puramente biológico superándolo para mejor integrarse como parte de un sistema médico coherente portador de una concepción propia del universo, y del hombre considerado como un ser (cuerpo) biológico, y como miembro de un cuerpo social que le incluye sin reducirlo.

Mediante este orientación del análisis no se esta tratando de reducir el problema de la enfermedad a una exclusiva dimensión social y cultural, ni tampoco de adscribir ninguna conexión causal ni dependencia entre estos rituales terapéuticos y curación. Tan solo se trata de subrayar el hecho de que lo que están mostrando estos ceremoniales y prácticas populares con fines curativos, a los que he aludido en la parte etnográfica del estudio, es sobre todo ese sistema complejo de creencias, valores, pensamientos, sentimientos y aspiraciones personales de nuestros pacientes y, por extensión, de nuestro pueblo gallego en especial la comunidad campesina, y no tanto la eficacia o no de tales remedios lugareños, ó el potencial curativo de nuestras variadas tipos de «augas milagreiras». Más que darnos razón de su eficacia curativa o resultados curativos reales, todas estas prácticas terapéuticas que han quedado mencionadas la dan muy eficientemente del sistema de cultura popular que detenta la sociedad que las conserva y, si se da el caso, aún pone en práctica con objeto de responder al problema de la enfermedad.

Todavía hoy, cuando un paisano nuestro ingresa en un Hospital con algún tipo de malestar, y ve dispuestos a intervenir sobre su mal unos «médiums» especiales (cirujanos, anestesistas, enfermeras, camilleros...), vestidos con unos uniformes especiales, y practicando unas técnicas curativas y unos lenguajes de oficio especiales que le resultan ajenos, nuestro paciente campesino no tiene claro que todo aquello le sea suficiente para tratar su enfermedad. Es en parte por esto que de un modo alternativo, esto es, como un procedimiento paralelo, aún hoy no sea nada difícil comprobar como nuestros enfermos echan mano también de los muy variados recursos naturales y culturales para conseguir el mismo fin. En el escenario terapéutico de nuestra sociedad actual, al margen de las clínicas de medicina oficial y de los balnearios y terapias propias de la medicina natural, sigue apareciendo todavía con más frecuencia de lo que habitualmente se cree, el viejo recurso de las estrategias domésticas y locales, en las que tienen cabida el subsistema ecológico con sus encrucijadas, caminos, prados, tierras, cultivos, árboles, flores, ríos, etc. y la acción «salutífera» del agua ritual proveniente del rocío, de los ríos, fuentes y del mar, todas ellas con capacidad de marcar semánticamente el ritual popular; y también otros elementos del subsistema ideológico de cultura 
como los exorcistas, arresponsadores, «pastequeiros», sabias, curanderas, 'Marías', 'viudas', 'entendidas' etc., y del subsistema de creencias centrado en los variados rezos, santos, espíritus bienhechores, fórmulas milagrosas, etc. así como los variadísimos procedimientos, gestos, fechas, números, y otros elementos cargados de un simbolismo religioso especial. Por lo demás, el pueblo con su enfermo, familia, vecinos, y los «sabios» $\mathrm{y}$ «sabias» locales que manipulan esos elementos y fórmulas invocadoras de los espíritus y las fuerzas del bien, aparecen ocupando el centro del escenario terapéutico local.

Una observación más atenta del empleo y manejo de cada una de estas aguas rituales que entran formando parte de los procedimientos terapéuticos populares, nos permite recalcar algunos aspectos de la cosmovisión de nuestro pueblo que se halla a la base de tales terapias sociales. Por lo que respecta al empleo del agua de río en este tipo de prácticas curativas, lo que hace el pueblo no es otra cosa que reutilizar esa antiquísima cosmovisión en la que estas aguas, como aguas vivas que son, constituían uno de los grandes ingredientes de rituales por su significación religiosa, derivada de la personificación de los ríos como divinidades. Se deberá recordar que el río Ganges era un río consagrado a Siva, o como el río Nilo es el río por excelencia de la Biblia, dotado de unas aguas saturadas de fuerza creadora de naturaleza y de vida, capaces de regenerar la vegetación y las cosechas anuales, y de dar prosperidad a las comunidades del entorno; también las aguas del río Jordán tenían la capacidad de reintegrar a los Judios bautizados en él en la nueva organización eclesial; y en Grecia clásica, «los ríos que bordean los templos de la Esculapio en Epidauros y Pérgamon» servían a los enfermos helenos para tomar en ellos baños rituales «esperando alcanzar la salud $\gg{ }^{70}$. De similar modo, en Galicia varios ríos de los que cruzan su geografía han sido dotados hace milenios de significación religiosa especial, y sus aguas discurren llenas de capacidad de hacer el ben, de matar la enfermedad y devolvernos la salud. Son aguas especiales por cuanto lavan, purifican, regeneran, dan vida, y por lo tanto son capaces de fecundar a la mujer estéril o curar un enfermo de un mal. Los rituales terapéuticos desarrollados en su seno nos evocan aquellos que los citados enfermos helenos

${ }^{70}$ LISON TOLOSANA, C.: Antropología social: Reflexiones incidentales. o.c., pág. 58.

"CUADERNOS DE ESTUDIOS GALLEGOS", Tomo XLI, Fascículo 106, Santiago 1993-94. 
practicaban en los suyos, o los de los judíos en el río Jordán llevando a cabo el ritual de paso a la nueva organización eclesial. Repensar así nuestras aguas es contribuir no solo a delimitar el especial modo de ver de nuestra población rural la generosidad de las aguas de sus ríos a las que vino atribuyendo una fortaleza y capacidad curativa eficaz, sino al conocimiento de nuestra más antigua cosmovisión y de nuestro pasado histórico, del que todas estas «aguas rituales» reciben su fuerza semántica y contenido simbólico. Personas y elementos, reglas y procedimintos, significados en presencia, todo ello sirve para unir nuestro contexto histórico más remoto al contexto presente de la práctica ritual, la diacronía a la sincronía, lo general-universal a lo específico-local. En el lugar del ceremonial curador se hallan en presencia actores y acompañantes, creencias, ideas, comportamientos y usos convencionales de siempre y de ahora asociados a la manipulación y uso de nuestras aguas rituales; unas aguas que son del rocío de la noche de San Juán, 'flor de agua' de manantiales previlegidados, aguas de río y mar escogidos, y no agua de lluvia que abundantemente inunda Galicia simplemente porque ésta no es valorada por nuestra tradición tanto como lo son las otras 'aguas rituales'.

En la mentalidad popular solo las aguas citadas aparecen con capacidad para conseguir la fertilidad la población estéril o recuperar la salud las personas enfermas, porque también solo en ellas moran las variadas series ce Encantos, Hadas, Xanas, Espíritus y fuerzas numinosas, con los que cuenta nuestro sistema simbólico ideacional, en las que tiene asignada residencia enterna en su seno. Por eso están dotadas de capacidad y propiedades especiales, de potencialidades y valores semánticos que ahora 'actores' y acompañantes del ritual terapeutico desvelan en el curso de la acción ceremonial, donde todo - espacios, elementos, comportamientos, experiencias culturales- tienen su mensaje de acuerdo con la forma de intervenir, y que se trata de un mensaje que los diferentes 'actores' que toman parte en el ritual han sabido desvelar, y que es el que sigue haciendo acudir a ellas e integrarlas en las diferentes prácticas curativas y de prevención del mal que aún practican los miembros de nuestra sociedad.

Ante la existencia del mal y la carencia de profesionales de la mendicina científica en su entorno rural, o ante el elevado coste que a veces suponía los servicios médicos en relación con las posibilidades económicas de la familia del enfermo, y sobre todo, ante la escasa formación científica generalizada en la población, el campesino gallego «ha reaccionado apropiándose y reelaborando segmentos de tradición terpéutica occidental:

"CUADERNOS DE ESTUDIOS GALLEGOS", Tomo XLI, Fascículo 106, Santiago 1993-94. 
el agua, ese significante nato, entre otros $\rangle^{71}$. Pero este uso terapéutico del agua, lo introduce nuestro pueblo en el ámbito del rito (acción) y del enunciado (palabra, fórmula ritual) de tal modo que, en este género de terápias populares, son los gestos y palabras, los haceres y decires los que adquieren primacía sobre el solo hacer (acto quirúrgico, inyección, receta) de la medicina científico-experimental. En la biomedicina es sobre todo el acto técnico del 'experto' la base principal de la eficacia terapéutica. En la medicina popular esa eficacia descansa sobre todo en el gesto y la palabra siendo indisociables ambos elementos del ritual curador. El sistema médico tradicional funciona -como lo muestra la documentación etnográfica aportada- con fórmulas, rezos y acción al unísono, de tal modo que palabra y gesto simultáneos son los que proveen el cremonial de sentido y fuerza salutífera eficáz. Ser incrédulo, dudar, no reproducir correctamente la palabra (fórmula mágica) y el gesto (procedimiento ritual) es, en este sistema de medicina popular, restar capacidad y eficacia terapéutica al ceremonal salutífero. En lo que atañe, por último, a la eficiencia salutífera de todos estos elementos del sistema de medicina tradicional, esto es, al resultado objetivo de curación de la enfermedad mediante estos procedimientos culturales, pasa algo similar a lo que sucede con los sistemas de la medicina científico-experimental y el de medicina natural. Dependiendo de las características de los pacientes y de su enfermedad, del nombre, procedencia y reputación del «médium», de las palabras significantes, los elementos y fórmulas que se ponen a disposición del «experto» (médico, curandero, ensalmador, etc.), para unos pacientes estos rituales son una fuente de alivio y tranquilidad que compensan la práctica efectiva del ritual terapéutico a que fué sometido; para otros son fuente de mejoría puesto que después de la ceremonia comienzan a sentir real mejoría, según manifiestan los testimonios recogidos de enfermos y actores del ritual, y para otros son, por último, una fuente de curación eficaz tal como expresan otros informantes de los referidos rituales.

Mucho antes que las gentes de nuestros pueblos iniciaran la peregrinación a las clínicas, hospitales y residencias sanitarias de la Seguridad Social, ya se habían organizado para ofrecer a sus enfermos hospitalidad en sus fuentes termales y alrededor de determinados manantiales y corrientes de aguas «milagreiras». Solamente cuando los médicos han ido

${ }^{71}$ LISON TOLOSANA, C.: «Variaciones en agua ritual», en: Actas del Cogreso Fiestas y Liturgia. Editorial Unversidad Complutense, Madrid, 1988. Pags.: 186-214. Pág. 210

"CUADERNOS DE ESTUDIOS GALLEGOS", Tomo XLI, Fascículo 106, Santiago 1993-94. 
incrementando la seguridad en su ciencia y acentuando las críticas a las prácticas de medicina natural y popular, estas prácticas inician su paulatina desaparición no concluída todavía. Pero deberemos decir que medicina científica, medicina natural, medicina popular, más que ser estrategias opuestas de curación, lo son complementarias; y por más que se hayan generalizado las tesis críticas contra estas prácticas, tachadas de «supersticiosas»e ineficaces, y siempre propias de gente ignorante ${ }^{72}$, tales prácticas desempeñaban -todavía desempeñan- un papel en la sociedad. De un modo similar a como la actual medicina oficial se puede considerar adecuada a las necesidades terapéuticas del hombre de hoy, mucho más individualista que solidario, en estas viejas prácticas de medicina popular lo era a las necesidades terapéuticas y afectivas de aquellos hombres de antaño, menos individualistas que los actuales. Acudir a una fuente, al río, al mar, para utilizar sus aguas en las terapias salutíferas, no implicaba oponerse a su cosmogonía ni a su concepción de la enfermedad. El grupo que allí iba, ni siquiera se comportaba de forma muy diferente a cuando acudía a estos lugares para lavar o para abastecer de agua el hogar, pués estos espacios, son enclaves rituales unas veces, de reencuentro de los lugareños otras, y siempre unos 'enclaves' de unificación de la vida social. Es, como ya expresé, la progresiva medicación el factor que aceleró la caída del recurso a estas prácticas de la medicina natural y popular, que acompañaron a nuestros hombres de campo desde su nacimiento hasta la muerte. Pero si hoy la angustia ante la presencia de la enfermedad, que es también la de la muerte, tal vez sea menor que antes gracias al avance de las técnicas de la biomedicina actual, las creencias y los miedos aún perduran en nuestros enfermos, más o menos justificados, más conscientes ó inconscientes, avivados por un contexto rural siempre ageno al medio hospitalario. Por eso no ha de parecer extraño que todas estas «aguas rituales» referidas en el estudio, y las prácticas terapéuticas a ellas asociadas, todavía sigan hoy dando seguridad y esperanzas últimas a un numeroso colectivo de enfermos gallegos, cuando los médicos y técnicos de la medicina científica la abandonan.

\footnotetext{
${ }^{72}$ Es conocida la tesis crítica contra estas prácticas 'supersticiosas' del médico lucense Rodríguez López, para el que todo este tipo de prácticas (terapéuticas, religiosas, populares...) llevadas a cabo en las fuentes, ríos y santuarios, son solo consecuencia de la imaginación e ingnorancia del hombre. Cfr. RODRÍGUEZ LÓPEZ, J.: Supersticiones en Galicia y preocupaciones vulgares. Ediciones Celta, Lugo, 1974. Pág. 37
} 